\title{
Prevalence of hiatal hernia by blinded multidetector CT in patients with idiopathic pulmonary fibrosis
}

\author{
I. Noth*, S.M. Zangan\#, R.V. Soares ", A. Forsythe๘, C. Demchuk*, S.M. Takahashi*, \\ S.B. Patel*, M.E. Strek*, J.A. Krishnan*, M.G. Patti ${ }^{\star}$ and H. MacMahon ${ }^{\#}$
}

ABSTRACT: Hiatal hernia $(\mathrm{HH})$ is associated with gastro-oesophageal reflux (GOR) and/or GOR disease and may contribute to idiopathic pulmonary fibrosis (IPF). We hypothesised that $\mathrm{HH}$ evaluated by computed tomography is more common in IPF than in asthma or chronic obstructive pulmonary disease (COPD), and correlates with abnormal GOR measured by pH probe testing.

Rates of HH were compared in three cohorts, IPF $(n=100)$, COPD $(n=60)$ and asthma $(n=24)$, and evaluated for inter-observer agreement. In IPF, symptoms and anti-reflux medications were correlated with diffusing capacity of the lung for carbon monoxide ( $D L, C O)$ and composite physiologic index $(\mathrm{CPI})$. HH was correlated with $\mathrm{pH}$ probe testing in IPF patients $(\mathrm{n}=14)$.

HH was higher in IPF (39\%) than either COPD $(13.3 \%, p=0.00009)$ or asthma $(16.67 \%$, $\mathrm{p}=0.0139)$. The $\mathrm{HH}$ inter-observer $\kappa$ agreement was substantial in IPF $(\kappa=0.78)$ and asthma $(\kappa=0.86)$, and moderate in COPD $(\kappa=0.42)$. In IPF, HH did not correlate with lung function, except in those on anti-reflux therapy, who had a better $D$ L,CO $(p<0.03)$ and CPI $(p<0.04)$. HH correlated with GOR as measured by DeMeester scores $(p<0.04)$.

$\mathrm{HH}$ is more common in IPF than COPD or asthma. In an IPF cohort, HH correlated with higher DeMeester scores, confirming abnormal acid GOR. Presence of $\mathrm{HH}$ alone was not associated with decreased lung function.

KEYWORDS: Computed tomography, gastro-oesophageal reflux, hiatal hernia, idiopathic pulmonary fibrosis, interstitial lung disease

diopathic pulmonary fibrosis (IPF) is the most common of the interstitial pneumonias [1] and has no effective therapy [2]. The pathophysiology of IPF involves recurrent epithelial injury and subsequent aberrant fibroblast proliferation [3] Abnormal gastro-oesophageal reflux (GOR) and GOR disease (GORD) have been recognised as risk factors for IPF [4] and may have a role in repeated epithelial injury and disease progression [5]. Although acid aspiration has been linked with the pathogenesis of IPF by some authors $[5,6]$, the mechanism and relationship of abnormal GOR/ GORD to causality, progression or treatment of IPF has not been adequately addressed. One report has cited an incidence of abnormal GOR of $87 \%$ when assessed by ambulatory $\mathrm{pH}$ monitoring [7], while use of anti-GOR therapy was associated with a stable course in another report [8]. However, questions regarding testing and treatment for
GOR/GORD in larger populations of patients with IPF remain unanswered.

The majority of patients with IPF have pathological reflux $[9,10]$; however, it is unclear what constitutes sufficient/abnormal reflux to cause damage to the lungs. In addition, the presence of symptoms does not distinguish between those with and without reflux. In general, reflux is associated with the presence of hiatal hernia $(\mathrm{HH})[11]$, which is known to alter the integrity of the lower oesophageal sphincter (LOS). As a result, $\mathrm{HH}$ has been weakly associated with episodes of micro-aspiration (acidic and non-acidic), diminished LOS pressures and increased risk of erosive oesophagitis [12]. In one case series, use of fundoplication in IPF patients with abnormal GOR/GORD and $\mathrm{HH}$ who failed medical therapy resulted in stabilisation of oxygen requirements [13].
AFFILIATIONS

Depts of *Medicine,

"Radiology, and

"Surgery, University of Chicago,

Chicago, IL, USA.

CORRESPONDENCE

I. Noth

Section of Pulmonary and Critical

Care Medicine

University of Chicago

5841 S. Maryland Ave

MC 6076

Chicago

IL 60637

USA

E-mail: inoth@medicine.

bsd.uchicago.edu

Received:

June 292010

Accepted after revision:

June 012011

First published online:

July 072011 
The presence of $\mathrm{HH}$ is classically determined using a barium oesophagram to identify the location of the LOS in relationship to the crus of the diaphragm. Modern computed tomography (CT) using continuous high-resolution helical acquisition provides an alternative and recognised method for evaluation of the anatomy of the oesophagus in relationship to the diaphragm, and thus determination of the presence of $\mathrm{HH}$ [14]. Although $\mathrm{HH}$ are routinely diagnosed on thoracic CT scans, the degree of accuracy and the level of agreement between radiologists has not been formally evaluated for this task.

Given the relationship between $\mathrm{HH}$ and GOR/GORD, we hypothesised that $\mathrm{HH}$ is more common in IPF patients than in two other lung diseases known to be associated with $\mathrm{HH}$ and abnormal GOR/GORD: asthma and chronic obstructive pulmonary disease (COPD) $[15,16]$. Asthma is associated with high rates of abnormal GOR/GORD and rates of $\mathrm{HH}$ of $\geqslant 50 \%$ [17], both of which are much higher than in the population in general. The prevalence of $\mathrm{HH}$ increases with both age and obstructive physiology, and in one study, was seen in $\leqslant 56 \%$ in the 7 th and 8th decades of life and in $\leqslant 84 \%$ of those with emphysema [18]. We thought that assessing $\mathrm{HH}$ in patients with lung disease would be more valuable as a control group than the general population because these populations have higher rates of abnormal GOR/GORD and are better matched for age and comorbidities.

We also hypothesised that high-resolution multidetector CT (MDCT) can reasonably diagnose $\mathrm{HH}$, as judged by interobserver agreement. We further hypothesised that the use of anti-reflux medications, such as proton pump inhibitors (PPIs) and histamine-2 receptor antagonists (H2RAs), in patients with IPF and $\mathrm{HH}$, may reduce lung injury as measured by pulmonary function and composite physiologic index (CPI), indicating a role for abnormal GOR/GORD as a cause of lung injury in IPF.

As it has been previously demonstrated in other diseases that $\mathrm{HH}$ is associated with increased acid exposure [11, 12], we sought to explain our findings by determining whether the presence of $\mathrm{HH}$ on MDCT is linked to an altered acidic exposure, as demonstrated with $\mathrm{pH}$ probe testing in patients with IPF.

Some of the results of this study were previously reported in abstract form at the American Thoracic Society (ATS) Conference in May 2009 [19].

\section{METHODS}

\section{Study population}

A retrospective analysis was conducted at the University of Chicago (Chicago, IL, USA). The study was approved by the Institutional Review Board of the University of Chicago.

The IPF cohort consisted of 180 patients seen in the Interstitial Lung Disease Clinic of the University of Chicago, between September 2005 and July 2008, who were consented and prospectively enrolled into a longitudinal database and selected by a single investigator (I. Noth). Only patients with an available CT scan $(n=123)$ and a verified diagnosis (by I. Noth and M.E. Strek) of IPF according to the ATS/European Respiratory Society (ERS) diagnostic criteria [4] were included, leaving a final total of 100 subjects. 37 subjects had a confirmed usual interstitial pneumonia (UIP) histopathology pattern on a surgical biopsy. The remaining subjects all had a typical UIP honeycomb pattern on CT that was diagnostic of IPF; after a thorough evaluation, there were no alternative diagnoses [20].

The asthma cohort consisted of 24 patients who met ATS criteria for the diagnosis of severe asthma [21]; the patients were consented and prospectively enrolled into a separate longitudinal database, and had undergone MDCT as part of their clinical evaluation.

The COPD cohort consisted of 240 patients with an International Classification of Diseases (ICD)-9 code for COPD. Patients were from a general pulmonary clinic and had undergone a recent MDCT scan. 60 cases were randomly selected as a cohort for the study.

The IPF oesophageal function testing (OFT) cohort consisted of 14 patients referred to the Swallowing Center at the University of Chicago, at a pulmonologist's discretion, between October 1, 2008 and October 1, 2010. All 14 patients had a verified diagnosis (by I. Noth, S.M. Takahashi and S.B. Patel) of IPF according to the ATS/ERS diagnostic criteria [4]. Seven of the 14 subjects had confirmed UIP histopathology on surgical biopsy and/or lung explants. The remaining seven subjects had a honeycomb pattern on $\mathrm{CT}$ felt to be definitive of IPF, and no alternative diagnoses.

\section{Determination of $\mathrm{HH}$}

All scans were performed on Philips CT scanners (Philips Healthcare, Bothell, WA, USA) with 64-slice machines used for the majority, and other cases were performed on 256-slice and 16slice units. All patients were scanned using helical acquisition during a single breath-hold at $120 \mathrm{kV}$ (or $140 \mathrm{kV}$ for exceptionally large patients), and $\mathrm{mA} \cdot \mathrm{s}^{-1}$ varied according to patient size and weight. Expiration and prone scans were acquired at $1.00 \mathrm{~mm}$ collimation with $10-\mathrm{mm}$ intervals. Images were reconstructed axially at 3-mm slice thickness with both B (standard) and D (detail) filters, and at 1-mm slice thickness with a D filter. Axial maximum intensity projection was reconstructed at $10-\mathrm{mm}$ thickness with a 5-mm overlap. Coronal slabs and minimum intensity projection images were also reviewed. Prone and expiration scans were reconstructed at $1-\mathrm{mm}$ thick with a D filter. Source images $(0.9 \mathrm{~mm})$ were archived in all cases.

MDCT scans were randomly ordered and reviewed independently by two chest radiologists (S.M. Zangan and $\mathrm{H}$. MacMahon), without prior knowledge of diagnosis, using axial and coronal images with mediastinal window settings. The presence of $\mathrm{HH}$ was determined by evaluation of the oesophagus in relation to the diaphragm, using recognised anatomical definitions (fig. 1). Each $\mathrm{HH}$ was classified as type I-IV, as previously described [22]. We recognised that these types were established by oesophageal barium studies or endoscopy, so we further divided type I HH into "possible", "probable" and "definite" grades, to establish a Likert scale for the level of confidence of interpretation. In all cohorts, a "present" HH was then defined as type I with "probable" or "definite" grades, and type II-IV, in which both radiologists agreed. "Absent" HH was defined as absent or type I with the "possible" grade. Cases with discordant readings between radiologists were labelled "indeterminate", and were removed from further analysis. Using this grading system, the prevalence of $\mathrm{HH}$ and a $\kappa$ statistic for agreement were calculated. 

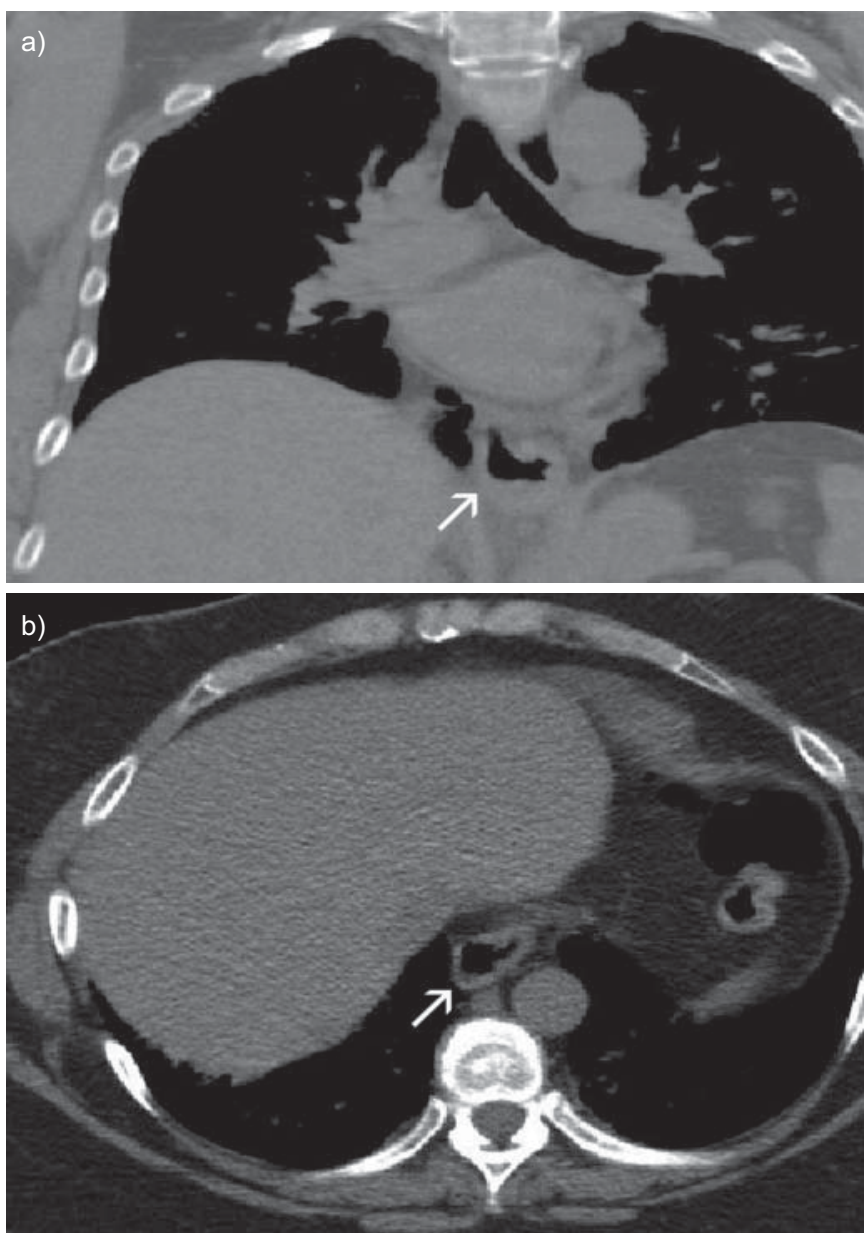

FIGURE 1. a) Coronal and b) axial images demonstrating an example of a hiatal hernia determined by computed tomography (thickened gastric mucosa above the level of the diaphragm).

\section{Relationship between $\mathrm{HH}$, lung severity, symptoms and} anti-reflux therapy in the IPF cohort

Study subjects underwent pulmonary function testing according to ATS guidelines [23]. Lung severity was assessed by forced vital capacity (FVC) \% predicted, diffusing capacity of the lung for carbon monoxide (DL,CO) \% pred and CPI, which has previously been shown to be associated with mortality [24].

Symptoms of reflux and the use of PPIs and H2RAs were determined via a questionnaire that was completed at the time of initial patient visit. In subjects with data from both pulmonary function testing and questionnaires, the use of anti-reflux medication and the association with the level of severity in patients with or without $\mathrm{HH}$ was evaluated.

\section{Relationship between HH on MDCT and OFT Oesophageal manometry}

Medications that interfere with oesophageal motility were discontinued $48 \mathrm{~h}$ prior to the procedure. After an overnight fast, oesophageal manometry was performed using a solid-state catheter with five circumferential pressure sensors (Sandhill Scientific, Highlands Ranch, CO, USA). LOS pressure and length were determined using the station pull-through technique, with $0.5-\mathrm{cm}$ increments between stations. Oesophageal peristalsis was measured with 10 swallows of $5 \mathrm{~mL}$ of water given at 30-s intervals. Peristaltic wave amplitude, duration and velocity were recorded at $3,8,13$ and $18 \mathrm{~cm}$ above the manometrically determined LOS. Peristaltic wave amplitude was independently calculated for the distal oesophagus ( 3 and $8 \mathrm{~cm}$ above the LOS, distal oesophageal wave amplitude) and for the proximal oesophagus (13 and $18 \mathrm{~cm}$ above the LOS, proximal oesophageal wave amplitude). Final manometric reporting was performed using the SPECHLER and CASTELL criteria [25].

\section{Ambulatory $\mathrm{pH}$ monitoring}

Prior to testing, acid-reducing medications were discontinued for 3 days for H2RAs and 10 days for PPIs. A dual-sensor $\mathrm{pH}$ probe was used, in which the lower sensor was placed $5 \mathrm{~cm}$ above the superior border of the manometrically determined LOS and the proximal sensor was placed $15 \mathrm{~cm}$ above the distal sensor. Patients were instructed to eat an unrestricted diet and avoid acid-suppressing medications during the study. Patients were given a diary to describe symptoms and events. Based on the collected data, a composite reflux score (DeMeester score) was calculated for the distal oesophagus. The data were analysed using a commercial software program (BioView; Sandhill Scientific). A DeMeester score $>14.7$ was considered abnormal [26]. Patients were considered to have abnormal proximal reflux if the acid exposure was $>1 \%$ [27].

\section{Statistical analysis}

Data are reported as mean $\pm \mathrm{SD}$, median (range) and proportions. Comparisons between clinical and radiological findings were made using the Chi-squared test and Fischer's exact test, as appropriate. OFT, symptoms, treatment, FVC \% pred, DL,CO $\%$ pred and CPI were analysed using unpaired, two-tailed ttests. Levels of agreement were analysed using $\kappa$ statistics [28].

\section{RESULTS}

\section{Demographics of IPF, COPD and asthma groups}

184 high-resolution (HR)CTs were reviewed in patients at the University of Chicago; 100 with IPF, 60 with COPD from the General Pulmonary Clinic and 24 with asthma from the Refractory Obstructive Lung Disease Clinic. The demographic and clinical characteristics of study subjects are shown in table 1. The percentage of male subjects in the IPF cohort was 70\%, 53\% in the COPD cohort and $25 \%$ in the asthma cohort. The mean \pm SD ages of each cohort at the time of MDCT collection were $67.5 \pm 9.0$ yrs for IPF, $68.5 \pm 8.6$ yrs for COPD and $52.8 \pm 17.4$ yrs for asthma.

The IPF OFT cohort consisted of 14 patients, nine of whom were male. The average age was $60.4 \pm 10.8$ yrs (table 2 ).

\section{Prevalence of $\mathbf{H H}$ in the IPF, COPD and asthma cohorts}

The rate of $\mathrm{HH}$ as defined by agreement between both radiologists was statistically significantly higher in IPF, at $39 \%$ (95\% CI 30.98-47.02\%), than either the COPD or asthma cohorts, at $13.3 \%$ (95\% CI 6.11-20.55\%; p < 0.00009$)$ and $16.67 \%$ (95\% CI 4.15-29.19\%; p<0.0139), respectively (table 1 ). The inter-observer $\kappa$ statistic of determination of $\mathrm{HH}$ by HRCT demonstrated substantial agreement $(\kappa=0.78)$ in IPF, moderate agreement $(\kappa=0.42)$ in COPD and substantial agreement $(\kappa=0.86)$ in asthma. 
TABLE 1 Demographic characteristics, inter-observer agreement and rates of hiatal hernia $(\mathrm{HH})$

\begin{tabular}{|c|c|c|c|c|}
\hline \multicolumn{5}{|l|}{ Demographic characteristics } \\
\hline Age yrs & 65.6 & 67.5 & 68.5 & 52.8 \\
\hline Males \% & 58.7 & 70.0 & 53.3 & 25.0 \\
\hline Level of agreement $\mathrm{\kappa}(95 \% \mathrm{Cl})$ & $0.70(0.59-0.81)$ & $0.78(0.66-0.90)$ & $0.42(0.17-0.67)$ & $0.86(0.60-1.00)$ \\
\hline
\end{tabular}

IPF: idiopathic pulmonary fibrosis; COPD: chronic obstructive pulmonary disease. ${ }^{*}: \mathrm{HH}$ rates compared with IPF.

\section{Evaluation of the level of disease severity and $\mathrm{HH}$ in the IPF} cohort

To analyse the relationship between $\mathrm{HH}$ and IPF, we examined cases in which there was both agreement between radiologist reviews and availability of pulmonary function data for

\begin{tabular}{|c|c|c|c|}
\hline & HH absent & HH present & $p$-value \\
\hline \multicolumn{4}{|l|}{ Demographics and PFTs } \\
\hline Subjects $n$ & 5 & 9 & \\
\hline Age yrs & 62 & 60 & \\
\hline Males $n$ & 3 & 6 & \\
\hline FVC $\%$ pred & 59.8 & 64.4 & NS \\
\hline$D \mathrm{~L}, \mathrm{CO} \%$ pred & 34.8 & 45.0 & NS \\
\hline \multicolumn{4}{|l|}{ Manometry } \\
\hline LOS pressure mmHg & $24.78 \pm 12.10$ & $23.28 \pm 12.41$ & 0.83 \\
\hline Hypotensive LOS & 20 & 20 & \\
\hline \multicolumn{4}{|l|}{$<14 \mathrm{mmHg} \%$} \\
\hline Total LOS length $\mathrm{cm}$ & $3.42 \pm 0.51$ & $2.39 \pm 0.80$ & 0.01 \\
\hline Abd LOS length $\mathrm{cm}$ & $2.40 \pm 1.47$ & $1.34 \pm 0.92$ & 0.20 \\
\hline UOS pressure $\mathrm{mmHg}$ & $32.28 \pm 12.18$ & $40.39 \pm 23.67$ & 0.43 \\
\hline \multicolumn{4}{|c|}{ Oesophageal $\mathrm{pH}$ findings } \\
\hline \multicolumn{4}{|l|}{ Proximal probe } \\
\hline Reflux events & $60.25 \pm 35.51$ & $65.44 \pm 65.92$ & 0.86 \\
\hline Events $>5 \mathrm{~min}$ & $1.50 \pm 1.73$ & $2.28 \pm 2.44$ & 0.53 \\
\hline Time $\mathrm{pH}<4 \%$ & $3.20 \pm 2.10$ & $4.28 \pm 3.23$ & 0.49 \\
\hline Time upright \% & $4.23 \pm 3.49$ & $6.34 \pm 5.58$ & 0.43 \\
\hline Time supine $\%$ & $1.38 \pm 1.70$ & $2.36 \pm 3.11$ & 0.48 \\
\hline \multicolumn{4}{|l|}{ Distal probe } \\
\hline Reflux events & $25.25 \pm 19.00$ & $58.86 \pm 64.98$ & 0.24 \\
\hline Events $>5 \mathrm{~min}$ & $0.00 \pm 0.00$ & $1.29 \pm 1.60$ & 0.08 \\
\hline Time $\mathrm{pH}<4 \%$ & $0.55 \pm 0.44$ & $2.82 \pm 3.06$ & 0.22 \\
\hline Time upright \% & $0.88 \pm 0.82$ & $4.04 \pm 3.79$ & 0.07 \\
\hline Time supine $\%$ & $0.08 \pm 0.15$ & $1.84 \pm 3.41$ & 0.22 \\
\hline DeMeester Score & $10.20 \pm 7.74$ & $22.79 \pm 11.26$ & 0.03 \\
\hline
\end{tabular}

Data are presented as mean $\pm \mathrm{SD}$, unless otherwise stated. $\mathrm{HH}$ : hiatal hernia; PFT: pulmonary function test; FVC: forced vital capacity; \% pred: \% predicted; $D L, C O$ : diffusing capacity of the lung for carbon monoxide; LOS: lower oesophageal sphincter; Abd: abdominal; UOS: upper oesophageal sphincter; NS: nonsignificant. analysis. Of the 100 cases with IPF, 11 were excluded as they were indeterminate for the presence or absence of $\mathrm{HH}$; 15 cases had incomplete pulmonary function data. The remaining 74 cases constituted the IPF cohort. Data on symptoms and the use of anti-reflux therapy were available in these 74 cases.

No differences were noted in age, race, sex, symptoms or use of anti-reflux medications between IPF patients with or without $\mathrm{HH}$ (table 3). Mean FVC \% pred, DL,CO \% pred and CPI did not differ significantly between groups (table 4). When IPF patients with $\mathrm{HH}$ were further examined by use or non-use of anti-reflux medications, significant differences were noted in the DL,CO \% pred which was $40.9 \pm 15.0$ in patients without therapy versus $55.7 \pm 19.9$ in patients with therapy $(\mathrm{p}<0.03)$. Similarly, the CPI demonstrated a difference with therapy: $56.0 \pm 13.5$ without therapy versus $44.8 \pm 15.0$ with therapy ( $<<0.04$; fig 2 ).

There were 33 subjects in a subgroup of IPF patients with $\mathrm{HH}$ and pulmonary function test results. Of the 14 not on antireflux medication and with $\mathrm{HH}, 11$ were Caucasian, two were Hispanic and one was African-American. Only one of these 14 patients noted reflux symptoms on our intake evaluation questionnaire. Four out of the 14 were on prednisone therapy at the time of evaluation. Of the 19 patients with $\mathrm{HH}$ on antireflux therapy, 16 were Caucasian, one was Asian and two were African-American. Eight out of the 19 noted active complaints of reflux on our intake evaluation questionnaire. Four out of the 19 were on prednisone therapy at the time of evaluation. 18 of the 19 were on PPIs and one was on an H2RA.

\section{HH and the IPF OFT cohort}

The demographic data for this group are presented in table 2. Analysis of manometry demonstrated a shortened total LOS length in those with $\mathrm{HH}$ on MDCT, at $2.39 \mathrm{~cm}$, compared with IPF patients without $\mathrm{HH}$ noted on MDCT, at $3.42 \mathrm{~cm}(\mathrm{p}<0.02)$. The distal $\mathrm{pH}$ probe demonstrated a significantly higher DeMeester score in the $\mathrm{HH}$ group of 22.79 compared with 10.20 for the non-HH group $(\mathrm{p}<0.04)$. Trends favouring increased acid exposure in the $\mathrm{HH}$ group were noted in the percentage of events in the upright position and in the events $>5$ min duration.

\section{DISCUSSION}

IPF is a complex disease with an unknown aetiology. Central to the current hypothesis of causation is an alveolar epithelial injury repair model involving serial lung injury and aberrant repair. Factors implicated in the injury process include genetic 
TABLE 3 Severity of disease in idiopathic pulmonary fibrosis (IPF) according to symptoms and use of anti-reflux medications

\begin{tabular}{|c|c|c|c|c|c|}
\hline IPF cohort & Subjects $\mathbf{n}$ & Age yrs & FVC \% pred & $D$ L,co \% pred & CPI \\
\hline Anti-reflux medication used & 35 & 68 & $69.0 \pm 18.5$ & $44.4 \pm 17.3$ & $53.7 \pm 14.4$ \\
\hline Reflux symptoms present ${ }^{\#}$ & 16 & 64 & $74.2 \pm 20.8$ & $50.5 \pm 23.4$ & $46.9 \pm 16.9$ \\
\hline Reflux symptoms absent & 58 & 67 & $67.7 \pm 16.5$ & $46.9 \pm 17.2$ & $51.9 \pm 13.5$ \\
\hline Anti-reflux medication used & 25 & 67 & $66.0 \pm 13.0$ & $49.9 \pm 17.4$ & $53.4 \pm 12.4$ \\
\hline
\end{tabular}

Data are presented as mean \pm SD, unless otherwise stated. None of the data were statistically significant. FVC: forced vital capacity; \% pred: \% predicted; $D L, C O$ : diffusing capacity of the lung for carbon monoxide; CPI: composite physiologic index. ${ }^{\#:} 15$ out of the 16 subjects were taking anti-reflux medication.

predisposition and environmental factors, such as tobacco smoke [4, 29]. Micro-aspiration may also have a causative or disease-modifying role in some patients. We sought to study: whether $\mathrm{HH}$, as typically evaluated by radiologists, could be reliably determined on MDCT; whether there was an increased prevalence of $\mathrm{HH}$ in patients with IPF compared with other common pulmonary diseases with known increased rates of abnormal GOR/GORD and HH, such as asthma and COPD; and whether treatment of abnormal GOR/GORD in patients with both IPF and $\mathrm{HH}$ was associated with disease severity as measured by pulmonary function. We then sought to determine whether there was a relationship between $\mathrm{HH}$ on MDCT and acid exposure.

Our approach demonstrates a methodology for determining the presence of $\mathrm{HH}$ using recognition of anatomical structures on HRCT. Traditionally, $\mathrm{HH}$ has been demonstrated using barium contrast oesophagram. This has given way to measurement of oesophageal acid reflux via $24-\mathrm{h} \mathrm{pH}$ probe monitoring and measurement of acidic and non-acidic reflux using oesophageal impedence. Even with barium contrast oesophagrams, there is no consensus regarding the differentiation of key anatomic structures such as the phrenic ampulla, which is physiological, from $\mathrm{HH}$, which is pathological. There is agreement that the lower oesophageal ring must be $\geqslant 1-2 \mathrm{~cm}$ above the level of the diaphragmatic hiatus for a diagnosis of $\mathrm{HH}$ [30]. The level of confidence in interpretation is therefore important. To maintain rigour in our interpretation, the radiologists read the CTs in a mediastinal window setting to minimise interpretation of the lung parenchyma; they also had no prior knowledge of the clinical diagnosis. Furthermore, we accepted only cases with complete agreement between radiologists for $\mathrm{HH}$ across all three cohorts. Our results demonstrated a prevalence of $\mathrm{HH}$ in subjects with IPF that was double that seen in asthma, a disease with rates of both abnormal GOR/GORD and HH known to be higher than in the population at large [16-18]. We also compared the prevalence of $\mathrm{HH}$ in IPF patients with that in COPD patients. As $\mathrm{HH}$ increases with advancing age [31] and with COPD [18], this cohort provided a useful comparator, superior to the general populace. The prevalence of $\mathrm{HH}$ in the IPF cohort was substantially higher than either group. Asthma and COPD, as obstructive lung diseases, may have increased intra-thoracic pressures that may predispose the diaphragm to pathophysiological changes favouring $\mathrm{HH}$. It is certainly reasonable that restrictive diseases may provide alterations to predispose to $\mathrm{HH}$ or that the $\mathrm{HH}$ is the reason for the development of the restriction. Either way, the rate of $\mathrm{HH}$ was highest in IPF subjects in the present study. Therefore, similar to the prior published data on abnormal GOR/GORD $[7,9], \mathrm{HH}$ had a much higher prevalence in IPF compared with that seen in other common pulmonary diseases.

It has been suggested that abnormal GOR/GORD plays a role in the pathogenesis of IPF [32]. RAGHU et al. [7] also demonstrated a high prevalence of abnormal GOR/GORD in an IPF cohort compared with an asthma cohort. In that prospective study, there was no correlation with disease severity. Indeed, a limitation of that study was that it was unclear what type and how much reflux might be injurious. In another study examining 18 subjects with severe end-stage IPF, the prevalence of abnormal GOR/ GORD by $\mathrm{pH}$ monitoring was $66 \%$; this was not associated with

\begin{tabular}{|c|c|c|c|c|c|}
\hline IPF cohort & Subjects $n$ & Age yrs & FVC $\%$ pred & $D L, C O \%$ pred & CPI \\
\hline HH absent & 44 & 66.5 & $70.1 \pm 17.9$ & $47.8 \pm 19.2$ & $50.7 \pm 14.5$ \\
\hline HH present & 33 & 67.0 & $70.1 \pm 18.4$ & $49.5 \pm 19.3$ & $49.6 \pm 15.2$ \\
\hline Anti-reflux medication used & 19 & 66.8 & $73.7 \pm 17.2$ & $55.7 \pm 19.9^{\#}$ & $44.8 \pm 15.0$ \\
\hline
\end{tabular}

Data are presented as mean \pm SD, unless otherwise stated. None of the data were statistically significant. FVC: forced vital capacity; \% pred: \% predicted; $D L, C O$ : diffusing capacity of the lung for carbon monoxide; CPI: composite physiologic index; Ns: nonsignificant. ${ }^{\#}: 15$ of the 16 subjects were taking anti-reflux medication. 

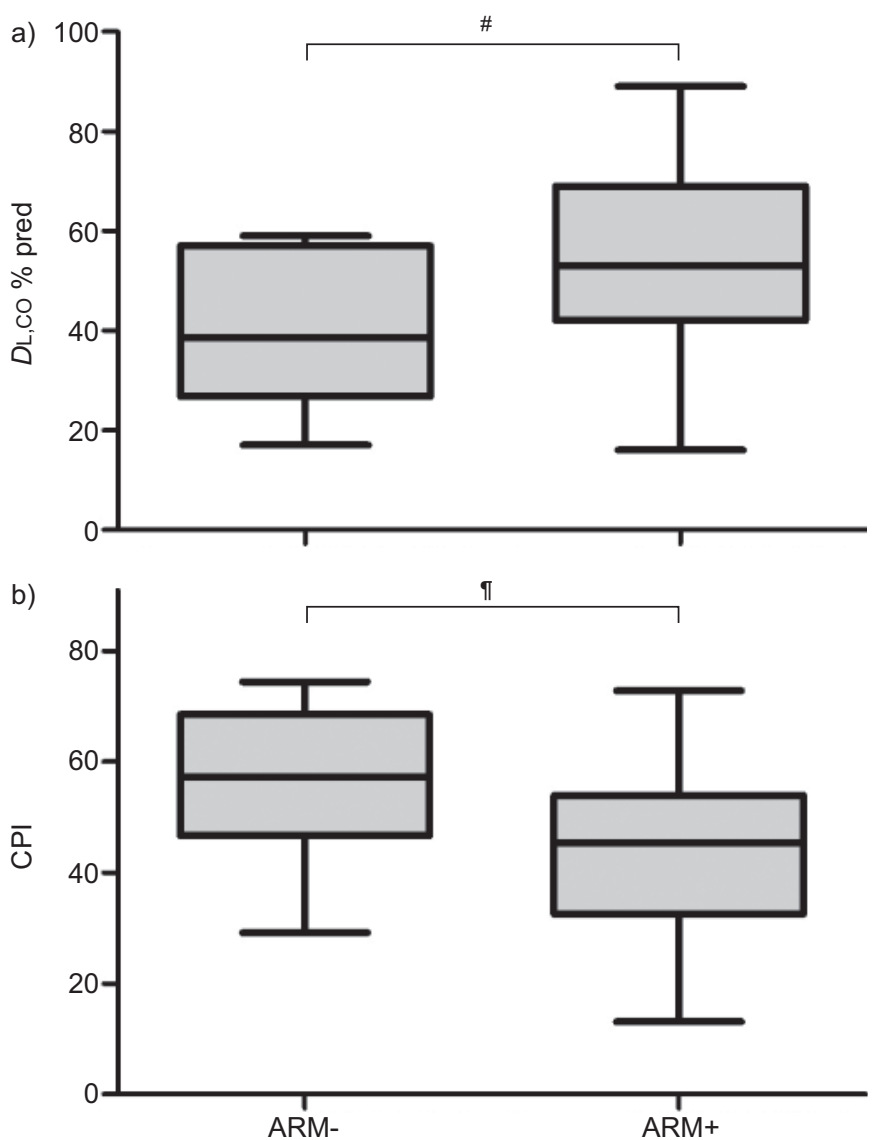

FIGURE 2. Idiopathic pulmonary fibrosis cohort with hiatal hernia as determined by inter-rater agreement on high-resolution computed tomography Disease severity was measured using a) diffusion capacity of the lung for carbon monoxide $(D \mathrm{~L}, \mathrm{CO}) \%$ predicted (\% pred) and b) composite physiologic index (CPI). Subjects were separated into those using anti-reflux medication (ARM+; $n=19$ ) and those not using anti-reflux medication (ARM-; $n=14$ ). Anti-reflux medication consisted of proton-pump inhibitors and histamine-2 blocking agents. Bars indicate median values. Box plots indicate median, and 25th-75th percentiles; whiskers indicate 5th-95th percentile. ${ }^{*}: p<0.03 ;{ }^{\circ}: p<0.04$.

symptoms but was associated with hypotensive LOS tone and abnormal oesophageal peristalsis [33]. To date, no study demonstrating the presence of abnormal GOR/GORD in subjects with IPF, either by symptoms or 24-h $\mathrm{pH}$ monitoring, has demonstrated any association with disease severity. Because of this, there has been a debate as to whether acid reflux disease or non-acidic particulate reflux is responsible for the damage caused by micro-aspiration.

In our study, of the 16 patients with active recorded symptoms, 15 were on anti-reflux therapy. 25 subjects on therapy were asymptomatic at the time of evaluation. There were no differences in the severity of lung disease when assessed only by use of anti-reflux medications. Nine out of 33 subjects with $\mathrm{HH}$ had symptoms, compared with seven out of 44 subjects without $\mathrm{HH}$. These data do not differ statistically. Eight out of the 19 subjects in the group with $\mathrm{HH}$ on anti-reflux therapy had symptoms, compared with only one out of the 14 in the group with $\mathrm{HH}$ who were not on anti-reflux therapy. Therefore, symptoms would seem to drive therapy, while symptoms and therapy alone correlate poorly with either disease severity, or with presence or absence of $\mathrm{HH}$.

We sought to test whether the presence of $\mathrm{HH}$ was associated with differences in the severity of disease in IPF. The pathophysiology of GOR and micro-aspiration is multi-factorial, with variable presentation within any patient group. Both an incompetent LOS and $\mathrm{HH}$ are associated with reflux disease [11] Classically, acid reflux is determined by duration, frequency and extent of distal oesophageal acid exposure by the DeMeester score [26], while detecting non-acid reflux is an inherent limitation of $\mathrm{pH}$ studies. Multichannel intraluminal impedance testing examines reflux events independently of $\mathrm{pH}$ [34].

To date, no study has demonstrated a correlation between disease severity in IPF and abnormal GOR/GORD. Indeed, in our cohort, $\mathrm{HH}$ alone was not associated with any difference in severity. We postulated that the frequent use of anti-reflux therapy in the community might temper or mitigate the damage caused by the refluxate, and prevent a decline in lung function. When we analysed differences in patients with $\mathrm{HH}$ with and without treatment, both the DL,CO \% pred and the CPI (as a measure of overall severity) were significantly better in treated patients. We explored the CPI as it included an adjustment for obstructive lung disease by incorporating forced expiratory volume in $1 \mathrm{~s}$, as well as FVC and DL,CO. There were no differences between treatment groups in the IPF patients without the presence of $\mathrm{HH}$ (data not shown). It is also possible that patients with abnormal GOR/GORD symptoms are diagnosed sooner and, therefore, have less severe disease. Our data demonstrate that there was no difference in the level of disease assessed with any measurement when patients were analysed according to the presence or absence of symptoms. In addition, there was no difference in severity in the groups that did or did not use anti-reflux medications, in those who were without symptoms or HH. These data suggest that treatment may mitigate a decline in lung function in subjects with IPF and HH only.

Our study does not answer several questions, such as whether the use of anti-reflux therapy is sufficient. Indeed, IPF subjects with $\mathrm{HH}$ who received anti-reflux therapy had similar pulmonary function to those without $\mathrm{HH}$. However, pulmonary function was lower in subjects with $\mathrm{HH}$ who did not receive anti-reflux therapy. We acknowledge that while acid reflux may be worse than non-acid reflux, non-acid reflux may still be important from the standpoint of disease pathogenesis and progression. This is supported by the high prevalence of nonacid reflux demonstrated in studies to date [10]. We also acknowledge the likelihood that micro-aspiration is not the only mechanism of alveolar injury. The prevalence of smoking, a factor clearly associated with IPF, is very high in IPF subjects [29]. Other environmental exposures are also possible contributors [29], and we did not examine these.

We recognise that an exact correlation should not be expected. However, what constitutes significant reflux is unclear in both the pulmonary [29] and the gastroenterology literature [35]. Several studies in non-IPF cases demonstrate that $\mathrm{HH}$ may result in a compromised LOS, leading to higher prevalence of refluxate, which may be acidic or non-acidic and either symptomatic or asymptomatic [15, 36, 37]. Whether a non-acidic asymptomatic refluxate is clinically meaningful is unknown. 
Our IPF OFT cohort confirms previous knowledge of the association between $\mathrm{HH}$ and increased acid exposure. An acknowledged mechanism is alteration of the LOS. Our findings indicate that IPF patients can be identified as having $\mathrm{HH}$ by CT, and that the presence of this finding is associated with a clinically higher DeMeester score and shorter LOS length.

Another question is whether $\mathrm{HH}$ is a contributor to IPF or whether $\mathrm{HH}$ is a result of lung restriction, leading to displacement of the diaphragm, which in turn causes $\mathrm{HH}$. If the latter were true, it would be expected that the severity of disease would be higher in all $\mathrm{HH}$ cases. However, in our study, only subjects with untreated $\mathrm{HH}$ had more severe pulmonary disease. It is possible that the higher rate of symptoms in the $\mathrm{HH}$ group on anti-reflux therapy leads to discovery of earlier disease, but this did hold true when the entire cohort was evaluated for reflux symptoms.

\section{Limitations}

Our study was observational, with data gathered retrospectively. It was not a blinded, randomised trial of anti-reflux therapy in IPF and did not evaluate patients over time. Specifically, we do not know when and if patients initiated anti-reflux therapy or if patients who were not on anti-reflux therapy at entry, initiated therapy at a later time-point. There were no controls for treatment, nor do we have any outcome data. Therefore, we have not explored or demonstrated long-term outcomes, such as longitudinal changes in pulmonary function tests, survival or acute exacerbations. While we observed that HH on MDCT correlated with greater acid exposure as measured by a DeMeester score on $\mathrm{pH}$ probe in a small cohort, the intensity, frequency and extent of abnormal acid reflux were not evaluated in the cohort at large. Thus, we cannot determine the longitudinal effect of anti-reflux medication as therapy for IPF, and we would caution against such an interpretation.

We can only speculate that anti-reflux treatment directed against abnormal acid GOR/GORD is helpful in the subset of patients, as the patients receiving pharmacological interventions to suppress abnormal acid GOR were associated with improved measurements of lung function (DL,CO and CPI). However, it must be noted that this speculation is based on the assumption that $\mathrm{HH}$ patients have abnormal acid reflux and that pharmaceutical intervention corrects this reflux if present.

\section{Conclusions}

Our study demonstrates that $\mathrm{HH}$ can be determined with very good agreement on MDCT in patients with IPF, and that the prevalence of $\mathrm{HH}$ is higher in IPF than in other common pulmonary diseases. Our study further suggests that in patients with IPF and HH on MDCT, anti-reflux treatment directed against abnormal GOR/GORD warrants further study to determine the effectiveness of anti-reflux therapy for patients with IPF.

\section{SUPPORT STATEMENT}

Supported by grants from: the Pulmonary Fibrosis Foundation Center of Excellence; the Coalition for Pulmonary Fibrosis; and the National Institute of Health/National Heart, Lung and Blood Institute (U10 HL080513).

\section{STATEMENT OF INTEREST}

Statements of interest for I. Noth and M.E. Strek can be found at www. erj.ersjournals.com/site/misc/statements.xhtml

\section{ACKNOWLEDGEMENTS}

We would like to thank S.R. White (University of Chicago, Chicago, IL, USA) for review of the manuscript and L. Sardin (University of Chicago) for maintaining the database.

\section{REFERENCES}

1 Raghu G, Weycker D, Edelsberg J, et al. Incidence and prevalence of idiopathic pulmonary fibrosis. Am J Respir Crit Care Med 2006; 174: 810-816.

2 Hubbard R, Johnston I, Coultas DB, et al. Mortality rates from cryptogenic fibrosing alveolitis in seven countries. Thorax 1996; 51: 711-716.

3 Harari S, Caminati A. Idiopathic pulmonary fibrosis. Allergy 2005; 60: 421-435.

4 American Thoracic Society/European Respiratory Society. International multidisciplinary consensus classification of the idiopathic interstitial pneumonias. Am J Respir Crit Care Med 2002; 165: 277-304.

5 Raghu G. The role of gastroesophageal reflux in idiopathic pulmonary fibrosis. Am J Med 2003; 115: Suppl. 3A, 60S-64S.

6 Schwartz DJ, Wynne JW, Gibbs CP, et al. The pulmonary consequences of aspiration of gastric contents at $\mathrm{pH}$ values greater than 2.5. Am Rev Respir Dis 1980; 121: 119-126.

7 Raghu G, Freudenberger TD, Yang S, et al. High prevalence of abnormal acid gastro-oesophageal reflux in idiopathic pulmonary fibrosis. Eur Respir J 2006; 27: 136-142.

8 Raghu G, Yang ST, Spada C, et al. Sole treatment of acid gastroesophageal reflux in idiopathic pulmonary fibrosis: a case series. Chest 2006; 129: 794-800.

9 Sweet MP, Herbella FA, Leard L, et al. The prevalence of distal and proximal gastroesophageal reflux in patients awaiting lung transplantation. Ann Surg 2006; 244: 491-497.

10 Sweet MP, Patti MG, Leard LE, et al. Gastroesophageal reflux in patients with idiopathic pulmonary fibrosis referred for lung transplantation. J Thorac Cardiovasc Surg 2007; 133: 1078-1084.

11 Fein M, Ritter MP, DeMeester TR, et al. Role of the lower esophageal sphincter and hiatal hernia in the pathogenesis of gastroesophageal reflux disease. J Gastrointestinal Surg 1999; 3: 405-410.

12 Lord RV, DeMeester SR, Peters JH, et al. Hiatal hernia, lower esophageal sphincter incompetence, and effectiveness of Nissen fundoplication in the spectrum of gastroesophageal reflux disease. J Gastrointest Surg 2009; 13: 602-610.

13 Linden PA, Gilbert RJ, Yeap BY, et al. Laparoscopic fundoplication in patients with end-stage lung disease awaiting transplantation. J Thorac Cardiovas Surg 2006; 131: 438-446.

14 Sillah K, Williams LR, Laasch HU, et al. Computed tomography overestimation of esophageal tumour length: implications for ratiotherapy planning. World J Gastointest Oncol 2010; 2: 197-204.

15 Bor S, Kitapcioglu G, Solak ZA, et al. Prevalence of gastroesophageal reflux disease in patients with asthma and chronic obstructive pulmonary disease. J Gastroenterol Hepatol 2010; 25: 309-313.

16 Harding SM, Guzzo MR, Richter JE. The prevalence of gastroesophageal reflux in asthma patients without reflux symptoms. Am J Respir Crit Care Med 2000; 162: 34-39.

17 Havemann BD, Henderson CA, El-Serag HB. The association between gastroesophageal reflux disease and asthma: a systematic review. Gut 2007; 56: 1654-1664.

18 Caskey CI, Zerhouni EA, Fishman EK, et al. Aging of the diaphragm: a CT study. Radiology 1989; 171: 385-389.

19 Noth I, Zangan S, Strek ME, et al. Hiatus hernia and IPF. Am J Respir Crit Care Med 2009; 179: A4064.

20 Hunninghake GW, Zimmerman MB, Schwartz DA, et al. Utility of a lung biopsy for the diagnosis of idiopathic pulmonary fibrosis. Am J Respir Crit Care Med 2001; 164: 193-196.

21 National Heart Lung and Blood Institute. Expert panel report 3: Guidelines for the diagnosis and management of asthma. www. 
nhlbi.nih.gov/guidelines/asthma/asthgdln.htm Date last updated: 2008. Date last accessed: June 10, 2010.

22 Skinner DB. Hernias (hiatal, traumatic, and congenital). In: Berk JE, ed. Gastroenterology. Vol. 4. Philadelphia, WB Saunders, 1985; pp. 705-716.

23 Miller MR, Hankinson J, Brusasco V, et al. Standardisation of spirometry. Eur Respir J 2005; 26: 319-338.

24 Wells AU, Desai SR, Rubens MB, et al. Idiopathic pulmonary fibrosis: a composite physiologic index derived from disease extent observed by computed tomography. Am J Respir Crit Care Med 2003; 167: 962-969.

25 Spechler SJ, Castel DO. Classification of eosophageal motility abnormalities. Gut 2001; 49: 145-151.

26 Johnson LF, DeMeester TR. Twenty-four hour $\mathrm{pH}$ monitoring of the distal oesophagus: a quantitative measure of gastroesophageal reflux. Am J Gastroenterol 1974; 62: 325-332.

27 Dobhan R, Castel DO. Normal and abnormal proximal eosophageal acid exposure: results of ambulatory dual-probe $\mathrm{pH}$ monitoring. Am J Gastroenterol 1993; 88: 25-29.

28 Viera AJ, Garrett JM. Understanding interobserver agreement: the kappa statistic. Fam Med 2005; 37: 360-363.

29 Idiopathic pulmonary fibrosis. diagnosis and treatment. International consensus statement. Am J Respir Crit Care Med 2000; 161: 646-664.
30 Dodds WJ, Walter B. Cannon lecture: Current concepts of esophageal motor function: clinical implications for radiology. Am J Roentgenol 1977; 128: 549-561.

31 Kang JY, Ho KY. Different prevalences of reflux oesophagitis and hiatus hernia among dyspeptic patients in England and Singapore. Eur J Gastroenterol Hepatol 1999; 11: 845-850.

32 Mays EE, Dubois JJ, Hamilton GB. Pulmonary fibrosis associated with tracheobronchial aspiration: a study of the frequency of hiatal hernia and gastroesophageal reflux in interstitial pulmonary fibrosis of obscure etiology. Chest 1976; 69: 512-515.

33 Patti MG, Tedesco P, Golden J, et al. Idiopathic pulmonary fibrosis: how often is it really idiopathic? J Gastrointest Surg 2005; 9: 1053-1058.

34 Hirano I, Richter JE. ACG practice guidelines: esophageal reflux testing. Am J Gastroenterol 2007; 102: 668-685.

35 Hak NG, Mostafa M, Salah T, et al. Acid and bile reflux in erosive reflux disease, non-erosive reflux disease and Barrett's oesophagus. Hepatogastroenterolog 2008; 55: 442-447.

36 Pandolfino JE, Shi G, Curry J, et al. Esophagogastric junction distensibility: a factor contributing to sphincter incompetence. Am J Physiol Gastrointest Liver Physiol 2002; 282: G1052-G1058.

37 van Herwaarden MA, Samsom M, Smout AJ. Excess gastroesophageal reflux in patients with hiatus hernia is caused by mechanisms other than transient LES relaxations. Gastroenterol 2000; 119: 1439-1446. 